Check for updates

Cite this: RSC Adv., 2019, 9, 10554

\title{
Highly selective and sensitive fluorescent probe for the rapid detection of mercury ions
}

\author{
Zujun $\mathrm{Xu},{ }^{a}$ Wenxiu Shi, ${ }^{a}$ Chengjun Yang, ${ }^{a}$ Jing $\mathrm{Xu}{ }^{a}$ Huapeng Liu, ${ }^{a}$ Jing $\mathrm{Xu} \mathrm{u}^{* \mathrm{~b}}$ \\ and Baocun Zhu (D) ${ }^{b}$
}

Mercury $(\mathrm{Hg})$ is one of the major toxic heavy metals, harmful to the environment and human health. Thus, it is significantly important to find an easy and quick method to detect $\mathrm{Hg}^{2+}$. In this study, we designed and synthesized a simple fluorescent probe with excellent properties, such as high sensitivity and selectivity, rapid response, and outstanding water solubility. When $\mathrm{Hg}^{2+}(5 \mu \mathrm{M})$ was added to the probe solution, it exhibited a very large fluorescent enhancement (about 350 -fold stronger than the free probe) with the help of hydrogen peroxide $\left(\mathrm{H}_{2} \mathrm{O}_{2}\right)$. Probe $\mathrm{HCDC}$ could quantitatively detect $\mathrm{Hg}^{2+}$ in the range of $0-10 \mu \mathrm{M}$ using the fluorescence spectroscopy method and the detection limit was measured to be about $0.3 \mathrm{nM}$ (based on a $3 \sigma /$ slope). Analytical application was also studied, and the probe $\mathrm{HCDC}$ exhibited excellent response to $\mathrm{Hg}^{2+}$ with the addition of $\mathrm{H}_{2} \mathrm{O}_{2}$ in real water samples. So, our proposed probe HCDC provided a practical and promising method for determining $\mathrm{Hg}^{2+}$ in the environment.

Received 24th January 2019

Accepted 20th March 2019

DOI: 10.1039/c9ra00622b

rsc.li/rsc-advances

\section{Introduction}

Heavy metal ion pollution has become a global environmental problem..$^{1-3}$ As a common metal element, mercury $(\mathrm{Hg})$ is extremely toxic and shows a great threat to the environment and human health due to its bioaccumulation, durability, and easy absorption by aquatic organisms. ${ }^{4-10}$ Once the mercury enters the organism, it will lead to the dysfunctions of the central nervous systems, the brain, and the kidneys. ${ }^{11-14}$ As we all know, the maximum contaminant level of mercury in drinking water is $2 \mathrm{ppb}(0.01 \mu \mathrm{M})$ which was set by the Environment Protection Agency (EPA). ${ }^{15-18}$ It can be seen that mercury could pose a serious threat to humans at very low concentrations. Thus, developing a convenient, rapid, highly selective and sensitive method for the determination of $\mathrm{Hg}^{2+}$ is vitally important.

Nowadays, several classical methods have been applied to determine $\mathrm{Hg}^{2+}$ including electrochemical analysis, atomic absorption/emission spectroscopy, electrochemical analysis, and inductively coupled plasma mass spectrometry. ${ }^{19-23}$ Though these methods are selective and accurate to detect ions, most of them require long time, expensive instruments, and tedious sample pre-treatment. ${ }^{24-26}$ Thus, the techniques of fluorescent probes were widely studied due to the advantages of highly selective, operational simplicity,

${ }^{a}$ School of Mathematics and Statistics, Ludong University, Yantai, China ${ }^{b}$ School of Water Conservancy and Environment, University of Jinan, Shandong Provincial Engineering Technology Research Center for Ecological Carbon Sink and Capture Utilization, Jinan, China. E-mail: 1426461661@qq.com; Fax: +86 531 82769235; Tel: +8653182769235 and relatively low-cost. ${ }^{27-33}$ Many fluorescent probes for detecting $\mathrm{Hg}^{2+}$ have been reported; however, most of them were still limited by the disadvantages of low sensitivity, bad water solubility, and long response time. ${ }^{34-38}$ So, a simple water-soluble fluorescent probe for determining $\mathrm{Hg}^{2+}$ with high sensitivity and quick response became our primary task.

Very recently, we have reported several carbonothioatebased fluorescent probe for detecting $\mathrm{Hg}^{2+}$. These probes respectively chose the 2-(2'-hydroxyphenyl)benzothiazole (HBT), ${ }^{39}$ dichlororesorufin, ${ }^{40}$ and seminaphthorhodafluor ${ }^{41}$ as the fluorophores, and a carbonothioate moiety was used as the recognition receptor. All these showed quick response and high selectivity for detecting $\mathrm{Hg}^{2+}$. In connection with our continuing research, we designed a new probe HCDC (Scheme 1) for detecting $\mathrm{Hg}^{2+}$ with superior properties in this paper, and the property of probe HCDC was compared with other reported studies in Table 1. A dimethylthiocarbamic ester group and 7-hydroxycoumarin were respectively chosen as the recognition receptor and the fluorophore. We assumed that the thioester group changed to ester moiety in the presence of $\mathrm{Hg}^{2+}$, and the rapid cleavage of ester group was achieved with the help of $\mathrm{H}_{2} \mathrm{O}_{2}$. As a result, this restored the blue fluorescence of 7-hydroxycoumarin. The experimental results demonstrated that this probe possessed the advantages of (1) a very low detection limit of $0.3 \mathrm{nM}$ (on the basis of $3 \sigma /$ slope); (2) quicker response to $\mathrm{Hg}^{2+}$; (3) excellent water solubility, selectivity and anti-interference; (4) practical applicability in real water samples. 
<smiles>CN(C)C(=S)Cl</smiles>

Scheme 1 Synthesis of probe HCDC.

\section{Experimental}

\subsection{Materials and general methods}

All the chemicals were gained from commercial suppliers and were used without further purification. The Sartorius Arium 611DI system can produce the ultra-pure water which was used during the entire process of the experiment. Column chromatography using Silica gel 200-300 mesh from the Qingdao Haiyang Chemical Co was used to purify the reaction product. The ${ }^{1} \mathrm{H}$ NMR and ${ }^{13} \mathrm{C}$ NMR were all recorded on the Bruker AV-400 spectrometer with chemical shifts reported as ppm (in DMSO- $d_{6}$, TMS as internal standard). Fluorescence spectra were gained from a Horiba FluoroMax-4 spectrophotometer. All the fluorescence spectra were uncorrected. Probe HCDC was prepared according to the previous paper. $^{42}$

\subsection{General procedure for analysis}

Stock solutions of probe HCDC $(1 \mathrm{mM})$ were prepared in ethanol. And the parent stock solutions $(1 \mathrm{mM})$ of $\mathrm{Hg}^{2+}$, other

Table 1 Comparison of Fluorescent Probes for $\mathrm{Hg}^{2+}$

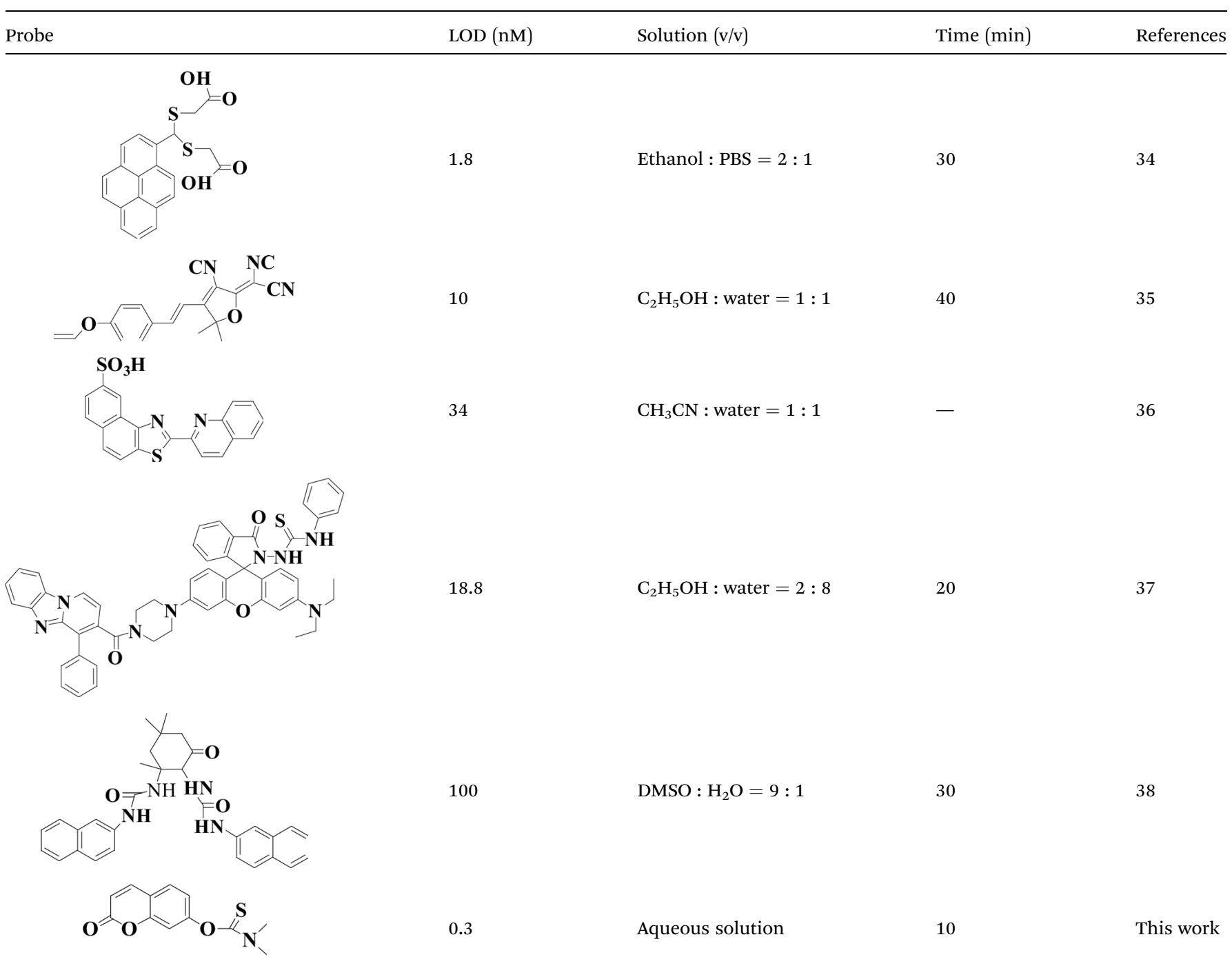


(a)
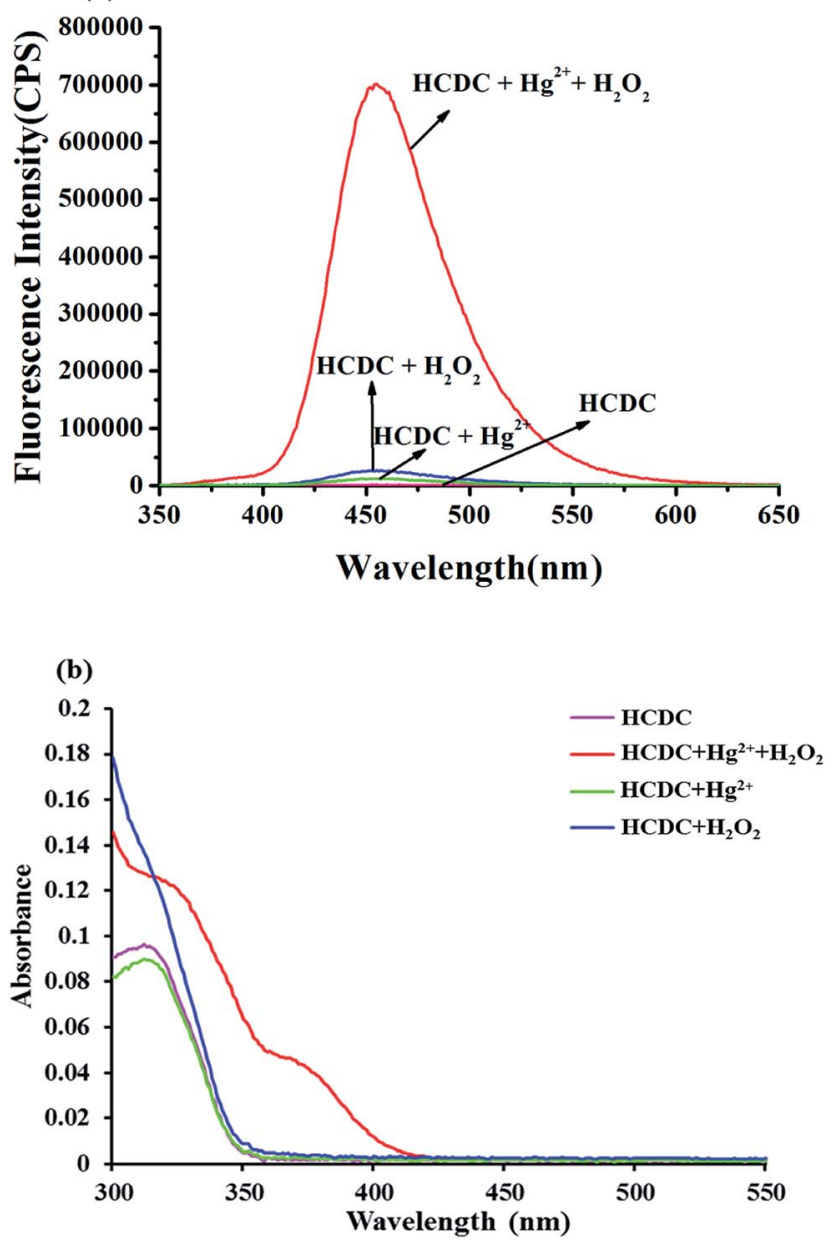

Fig. 1 Fluorescence spectra (a) and absorption spectra (b) of probe $\mathrm{HCDC}(5 \mu \mathrm{M})$ toward $\mathrm{Hg}^{2+}(5 \mu \mathrm{M})$ and $\mathrm{H}_{2} \mathrm{O}_{2}(3 \mathrm{mM})$ under the ultrapure water containing HEPES (5 mM, pH 7.4).

metal ions and common anions species $(10 \mathrm{mM})$ were prepared in ultrapure water. The test solution contained $50 \mu \mathrm{L}$ of the probe stock solution and moderate amount of each stock solution, and eventually diluted to $10 \mathrm{~mL}$ in a test tube with $100 \%$ ultrapure water containing HEPES (5 mM, pH 7.4).
Before $\mathrm{Hg}^{2+}$ and other ions were added to the test solution, $\mathrm{H}_{2} \mathrm{O}_{2}(3 \mathrm{mM})$ was added. All the tests were conducted at room temperature $\left(25^{\circ} \mathrm{C}\right)$.

\subsection{Determination of the detection limit}

According to the previous paper, ${ }^{43,44}$ the method of fluorescence titration was used to calculate the detection limit. The fluorescence emission spectrum of probe HCDC was measured by fifteen times in the absence of $\mathrm{Hg}^{2+}$ in order to achieve the standard deviation of blank measurement. To gain the slope, the fluorescence intensity at $455 \mathrm{~nm}$ was plotted as a concentration of $\mathrm{Hg}^{2+}$. Therefore, the formula for calculating the detection limit is described as following:

$$
\text { Detection limit }=3 \sigma / k
$$

where $\sigma$ is the standard deviation of the five spectrums among the fifteen spectrums which peaks were nearest, $k$ is the slope between the $\mathrm{Hg}^{2+}$ concentration versus the fluorescence intensity.

\subsection{Analytical application}

Three water samples were chosen to test the analytical application of the probe HCDC. One water sample was collected from Jia Zi Lake, University of Jinan, China, and the other two samples were respectively collected from the Xiu Jiang River and Yellow River, at Jinan, China. All the samples needed to filter through filter paper before the measurement.

\section{Results and discussion}

\subsection{Characteristic spectra}

In this paper, the fluorescence and absorption spectra of probe HCDC was shown as Fig. 1. In the absence of $\mathrm{Hg}^{2+}$ and $\mathrm{H}_{2} \mathrm{O}_{2}$, the probe solution exhibits a very weak fluorescence emission peak at $455 \mathrm{~nm}$. When only $\mathrm{Hg}^{2+}$ was added to the probe solution, the reaction was very slow. And, the reaction was not carried out when only the $\mathrm{H}_{2} \mathrm{O}_{2}$ was added. Once $\mathrm{Hg}^{2+}$ and

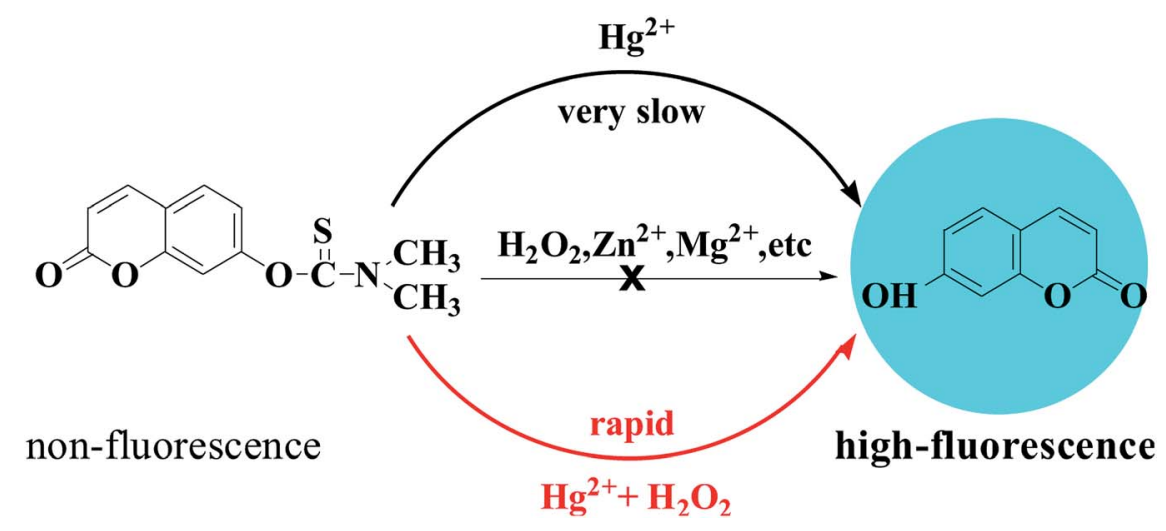

Scheme 2 Reaction Mechanism of probe $\mathrm{HCDC}$ for $\mathrm{Hg}^{2+}$ with the help of $\mathrm{H}_{2} \mathrm{O}_{2}$. 


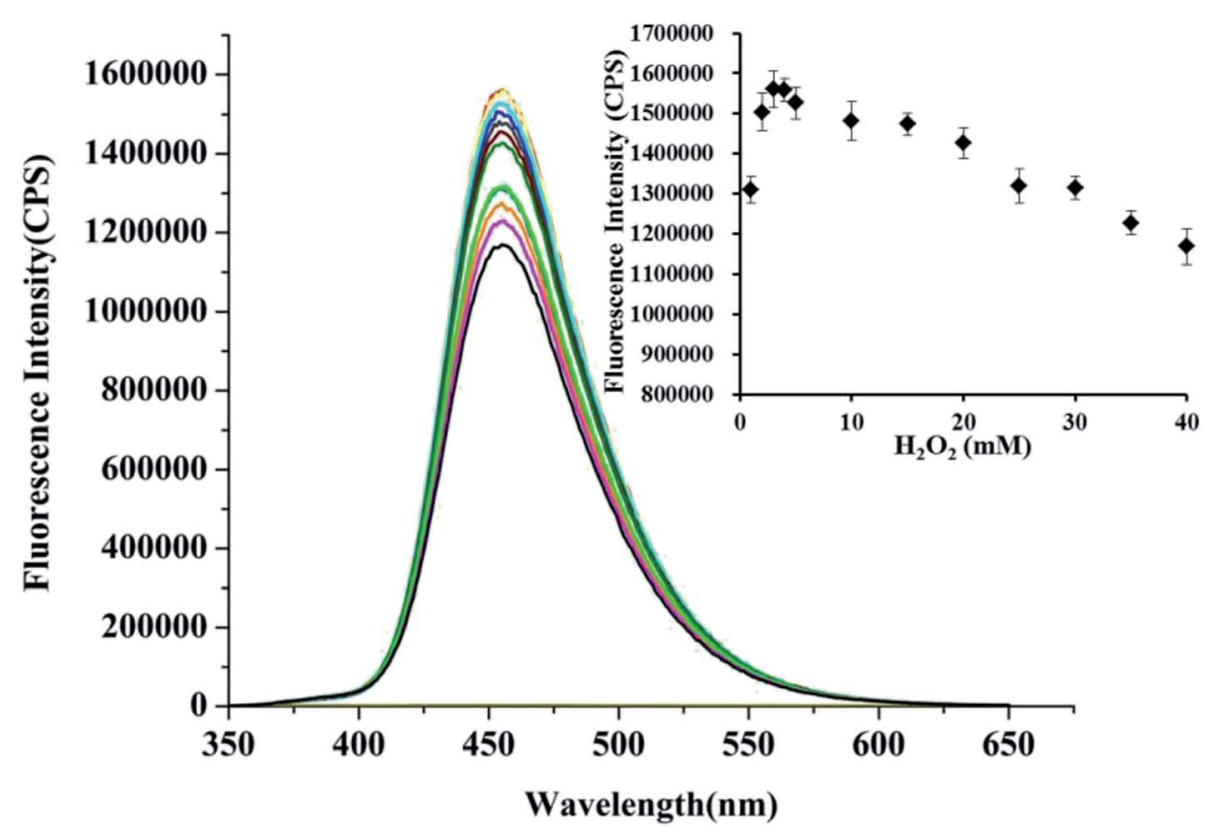

Fig. 2 Fluorescence spectra of probe $\mathrm{HCDC}(5 \mu \mathrm{M})$ in the presence of $\mathrm{Hg}^{2+}(5 \mu \mathrm{M})$ and different concentrations of $\mathrm{H}_{2} \mathrm{O}_{2}$ (final concentration: 0 , 1 , $2,3,4,5,10,15,20,25,30,35,40 \mathrm{mM})$ under HEPES $(5 \mathrm{mM}, \mathrm{pH} 7.4)$ aqueous solution. Excitation wavelength $=330 \mathrm{~nm}$. Error bar $=\mathrm{RSD}(n=3)$.

$\mathrm{H}_{2} \mathrm{O}_{2}$ were all added to the probe HCDC solution, the maximum fluorescence emission peak exhibits a very large enhancement at $455 \mathrm{~nm}$ (Fig. 1a). The fluorescence intensity peak of the probe solution containing $\mathrm{Hg}^{2+}$ and $\mathrm{H}_{2} \mathrm{O}_{2}$ was about 350 -fold stronger than that of the blank probe solution. Meanwhile, in the absorption spectra, with the addition of $\mathrm{Hg}^{2+}$ and $\mathrm{H}_{2} \mathrm{O}_{2}$, the probe solution exhibited a new absorption peak at $364 \mathrm{~nm}$ (Fig. 1b). The result showed that $\mathrm{Hg}^{2+}$ could generate the cleavage of an eater group in the presence of $\mathrm{H}_{2} \mathrm{O}_{2}$ (Scheme 2). ${ }^{40}$

\subsection{Effect of $\mathrm{H}_{2} \mathrm{O}_{2}$}

Different concentrations of $\mathrm{H}_{2} \mathrm{O}_{2}$ was respectively added to the solution of probe $\mathbf{H C D C}(5 \mu \mathrm{M})$ and $\mathrm{Hg}^{2+}(5 \mu \mathrm{M})$ in the aqueous solution which contained HEPES ( $5 \mathrm{mM}, \mathrm{pH}$ 7.4). It was shown in inset of Fig. 2, the fluorescence intensity was increased first and then decreased with the increasing concentrations of $\mathrm{H}_{2} \mathrm{O}_{2}$ (the range of 1 to $40 \mathrm{mM}$ ). The enhancement of fluorescence reached the maximum when the concentration of $\mathrm{H}_{2} \mathrm{O}_{2}$ was $3 \mathrm{mM}$. The results implied that the low concentration of $\mathrm{H}_{2} \mathrm{O}_{2}$ (1 to $3 \mathrm{mM}$ ) could promote the cleavage of ester group and amplify the response of probe $\mathrm{HCDC}$ to $\mathrm{Hg}^{2+}$. But when the concentration is over $3 \mathrm{mM}$ ( 4 to $40 \mathrm{mM}$ ), $\mathrm{H}_{2} \mathrm{O}_{2}$ will inhibit the response of probe $\mathbf{H C D C}$ to $\mathrm{Hg}^{2+}$. Thus, we chose $3 \mathrm{mM} \mathrm{H}_{2} \mathrm{O}_{2}$ as the amplification reagent in the detection of $\mathrm{Hg}^{2+}$.

\subsection{Time dependence of detecting $\mathbf{H g}^{2+}$}

Response time is a significant element to test the effect of the probe. So, the response time of probe HCDC was investigated under the analytical conditions which were mentioned above. The result was shown in Fig. 3. When only $\mathrm{Hg}^{2+}$ was added to
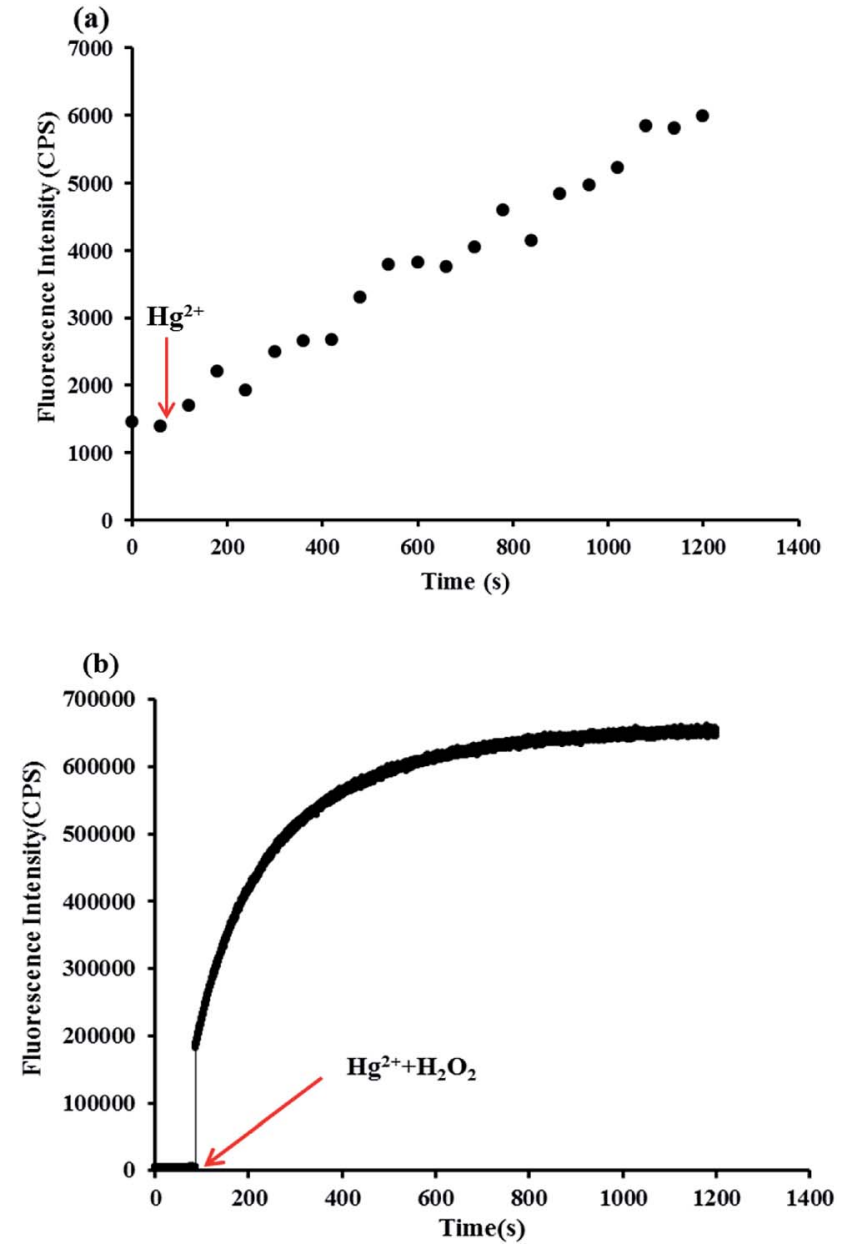

Fig. 3 Reaction time for probe $\mathrm{HCDC}(5 \mu \mathrm{M})$ with the addition of only $\mathrm{Hg}^{2+}(5 \mu \mathrm{M})(\mathrm{a})$, and $\mathrm{Hg}^{2+}(5 \mu \mathrm{M})$ and $\mathrm{H}_{2} \mathrm{O}_{2}(3 \mathrm{mM})(\mathrm{b})$. 


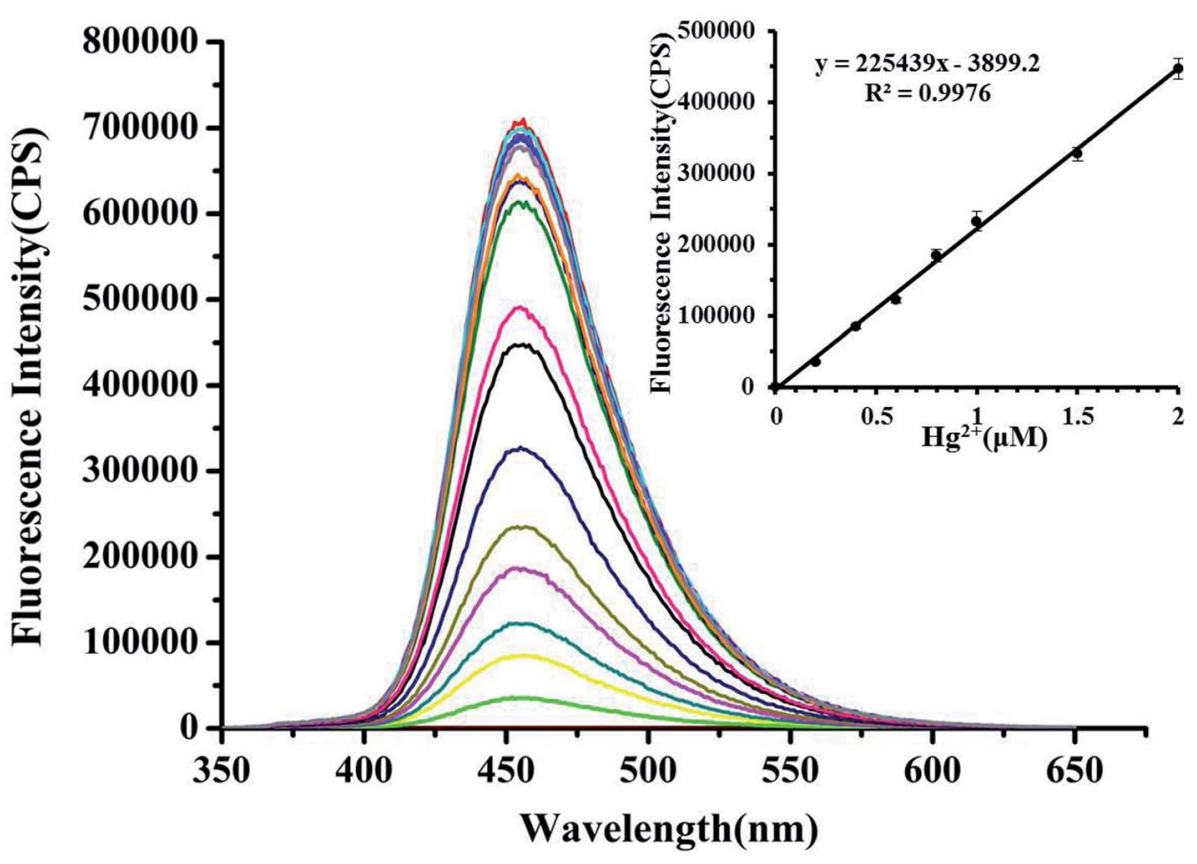

Fig. 4 Fluorescence spectra of probe $\mathrm{HCDC}(5 \mu \mathrm{M})$ toward the various concentrations of $\mathrm{Hg}^{2+}$ (final concentration: 0, 0.2, 0.4, 0.6, 0.8, 1, 1.5, 2, $2.5,3,3.5,4,4.5,5,6,7,8,9,10 \mu \mathrm{M})$ and $\mathrm{H}_{2} \mathrm{O}_{2}(3 \mathrm{mM})$. The fluorescence intensity at $455 \mathrm{~nm}$ of probe HCDC increased with the increasing concentrations of $\mathrm{Hg}^{2+}$. Excitation wavelength $=330 \mathrm{~nm}$, emission wavelength $=455 \mathrm{~nm}$. Conditions: in HEPES (5 mM, pH 7.4). Solution: ultrapure water. Error bar $=$ RSD $(n=3)$.

the probe solution, the reaction was very slow. While, the fluorescence intensity at $455 \mathrm{~nm}$ was increased as soon as $\mathrm{Hg}^{2+}$ and $\mathrm{H}_{2} \mathrm{O}_{2}$ were added, and increased gradually until the reaction time exceeded $10 \mathrm{~min}$. Thus, all the measurements of the spectrum were carried out 10 minutes after the addition of $\mathrm{Hg}^{2+}$. The results showed that the probe HCDC could provide a rapid analytical method for detecting $\mathrm{Hg}^{2+}$.

\subsection{Quantification of $\mathbf{H g}^{2+}$}

As shown in Fig. 4, the continuous enhancement of fluorescence intensity at $455 \mathrm{~nm}$ can be seen with the continuous addition of $\mathrm{Hg}^{2+}$ (the range of 0 to $10 \mu \mathrm{M}$ ). And, there was a good linearity $\left(y=225439 x+3899.2, R^{2}=0.998\right)$ between the $\mathrm{Hg}^{2+}$ concentrations of $0-2 \mu \mathrm{M}$ and the fluorescence intensity with a detection limit of $0.3 \mathrm{nM}$ (based on $3 \sigma /$ slope). The detection limit of the probe HCDC was far lower than the standard of $\mathrm{Hg}^{2+}$ $(10 \mathrm{nM})$ in drinking water which set up by the Environmental Protection Agency (EPA). The above results showed that the probe HCDC could detect $\mathrm{Hg}^{2+}$ quantitatively by the fluorescence spectrometry method with excellent sensitivity.

\subsection{Selectivity to $\mathbf{H g}^{2+}$}

High selectivity is also an important factor for an excellent probe. The selectivity of HCDC toward $\mathrm{Hg}^{2+}$ was evaluated under the above-mentioned conditions. The effect of the metal ions $\left(\mathrm{Mg}^{2+}, \mathrm{Zn}^{2+}, \mathrm{Ni}^{2+}, \mathrm{Ca}^{2+}, \mathrm{Na}^{+}, \mathrm{K}^{+}, \mathrm{Pb}^{2+}, \mathrm{Cd}^{2+}, \mathrm{Cr}^{6+}\right.$, $\left.\mathrm{Fe}^{2+}, \mathrm{Fe}^{3+}, \mathrm{Sn}^{2+}\right)$ and the common anions species $\left(\mathrm{NO}_{2}{ }^{-}\right.$, $\mathrm{NO}_{3}{ }^{-}, \mathrm{HCO}_{3}{ }^{-}, \mathrm{H}_{2} \mathrm{PO}_{4}{ }^{-}, \mathrm{F}^{-}, \mathrm{CO}_{3}{ }^{2-}, \mathrm{Cl}^{-}, \mathrm{SO}_{4}{ }^{2-}$ ) on fluorescence spectra of probe $\mathbf{H C D C}$ were investigated. Firstly, $\mathrm{Hg}^{2+}$, other metal ions and common anions species were respectively added to the solution, and only $\mathrm{Hg}^{2+}$ resulted in a considerable fluorescence enhancement (Fig. 5a and c). The results exhibited that HCDC possesses high selectivity toward $\mathrm{Hg}^{2+}$.

The interference of the metal ions and common anions species on the detection of $\mathrm{Hg}^{2+}$ was also studied. Even though the mental ions and common anions species were respectively existed in the solution, the probe HCDC also had a good response to $\mathrm{Hg}^{2+}$ (Fig. $5 \mathrm{~b}$ and $\mathrm{d}$ ). These studies clearly indicated that the probe HCDC could be used for the selective detection of $\mathrm{Hg}^{2+}$ without interference from anions.

\subsection{Analytical application}

Based on the above results, the probe HCDC owned the excellent properties containing a very low detection limit, quicker response, excellent water solubility, selectivity and anti-interference. So, we attempted to investigate the practical application of the probe for the selective detection of $\mathrm{Hg}^{2+}$ in three real water samples. The results were shown in Table 2. At first, there were no $\mathrm{Hg}^{2+}$ in three water samples, and then $2 \mu \mathrm{M}, 5 \mu \mathrm{M}$, or $10 \mu \mathrm{M} \mathrm{Hg}^{2+}$ was respectively added to the solution of real water ( $5 \mathrm{mM}$, HEPES, $\mathrm{pH}$ 7.4) containing $5 \mu \mathrm{M}$ probe HCDC and $3 \mathrm{mM} \mathrm{H}_{2} \mathrm{O}_{2}$. Every sample was repeatedly configured and tested for 3 times. Therefore, we obtained a good method for detecting $\mathrm{Hg}^{2+}$ in the environment. 

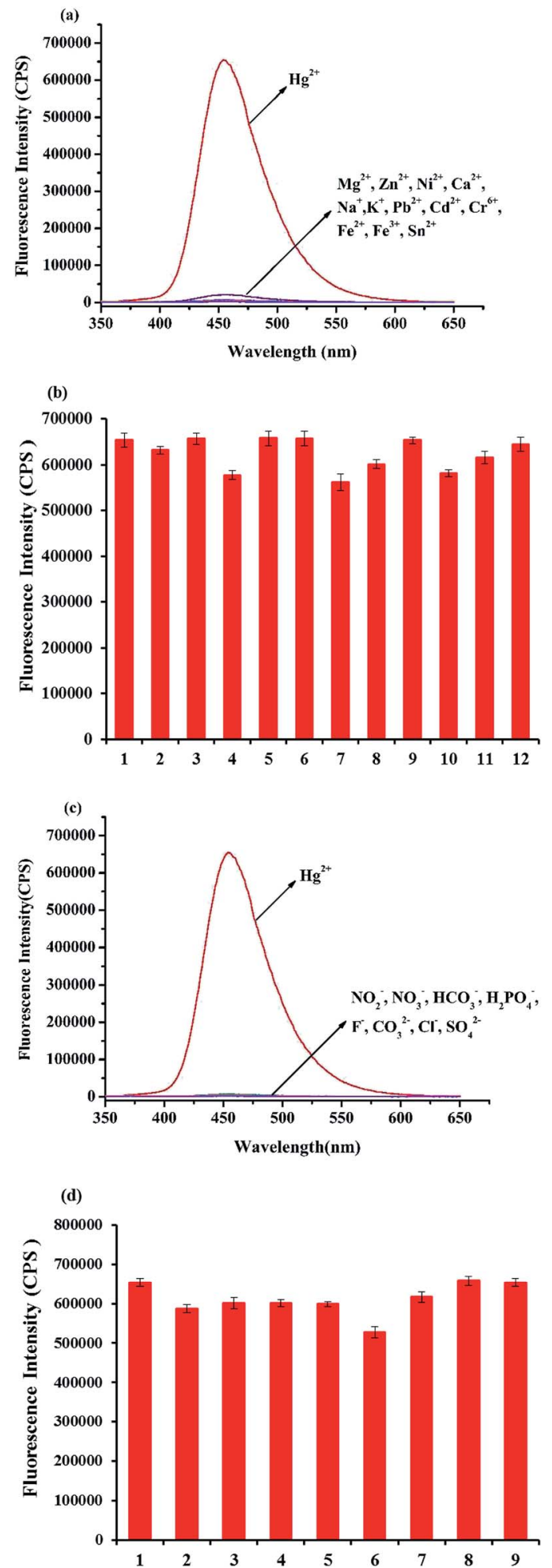

Fig. 5 (a) Fluorescence responses of probe $\mathrm{HCDC}(5 \mu \mathrm{M})$ toward $\mathrm{Hg}^{2+}(5$ $\mu \mathrm{M})$, and other metal ions $(100 \mu \mathrm{M})$. (b) Fluorescence responses of probe $\mathrm{HCDC}$ toward $\mathrm{Hg}^{2+}$ and in presence of other metal ions. (1) $\mathrm{Hg}^{2+}$; (2) $\mathrm{Mg}^{2+}$; (3) $\mathrm{Zn}^{2+}$; (4) $\mathrm{Sn}^{2+}$; (5) $\mathrm{Ca}^{2+}$; (6) $\mathrm{Na}^{+}$; (7) $\mathrm{Fe}^{3+}$; (8) $\mathrm{Pb}^{2+}$; (9) $\mathrm{Cd}^{2+}$; (10) $\mathrm{Fe}^{2+} ;$ (11) $\mathrm{K}^{+} ;$(12) $\mathrm{Ni}^{2+}$. (c) Fluorescence responses of $\mathrm{HCDC}(5 \mu \mathrm{M})$ toward $\mathrm{Hg}^{2+}(5 \mu \mathrm{M})$, and common anions species $(100 \mu \mathrm{M})$. (d) Fluorescence responses of probe $\mathrm{HCDC}$ toward $\mathrm{Hg}^{2+}$ and in presence of other common anions species (1) $\mathrm{Hg}^{2+}$; (2) $\mathrm{NO}_{2}^{-}$; (3) $\mathrm{NO}_{3}^{-}$; (4) $\mathrm{HCO}_{3}^{-}$; (5) $\mathrm{H}_{2} \mathrm{PO}_{4}{ }^{-}$; (6) $\mathrm{F}^{-}$; (7) $\mathrm{CO}_{3}{ }^{2-}$; (8) $\mathrm{Cl}^{-}$; (9) $\mathrm{SO}_{4}{ }^{2-}$. The solution: in $\mathrm{H}_{2} \mathrm{O}_{2}(3 \mathrm{mM})$, HEPES ( $5 \mathrm{mM}, \mathrm{pH}$ 7.4) aqueous solution. Error bar $=\mathrm{RSD}(n=3)$.
Table 2 Analysis results of $\mathrm{Hg}^{2+}$ in three real water samples ${ }^{a}$

\begin{tabular}{llllll}
\hline $\begin{array}{l}\text { Real water } \\
\text { sample }\end{array}$ & $\begin{array}{l}\text { Found } \\
\mathrm{Hg}^{2+}\end{array}$ & $\begin{array}{l}\text { Addition } \\
\mathrm{Hg}^{2+}(\mu \mathrm{M})\end{array}$ & Found $(\mu \mathrm{M})$ & Recovery $(\%)$ & $\begin{array}{l}\text { RSD } \\
(n=3)(\%)\end{array}$ \\
\hline \multirow{2}{*}{ Sample A } & No & 2 & $1.82 \pm 0.06$ & 91.06 & 2.89 \\
& & 5 & $4.52 \pm 0.11$ & 90.47 & 2.10 \\
& & 10 & $9.61 \pm 0.40$ & 96.06 & 4.02 \\
Sample B & No & 2 & $1.85 \pm 0.11$ & 92.52 & 5.36 \\
& & 5 & $4.97 \pm 0.29$ & 99.33 & 5.83 \\
& & 10 & $10.11 \pm 0.25$ & 101.11 & 2.51 \\
Sample C & No & 2 & $2.24 \pm 0.13$ & 111.93 & 6.56 \\
& & 5 & $5.15 \pm 0.21$ & 102.96 & 4.19 \\
& & 10 & $9.73 \pm 0.37$ & 97.28 & 3.72
\end{tabular}

${ }^{a}$ Sample A, lake water from JiaZi Lake, University of Jinan; sample B, from the Xiu Jiang River, at Jinan, China; sample C, from the Yellow River, at Jinan, China.

\section{Conclusion}

In a word, we have designed and synthesized a highly sensitive and selective probe for detecting $\mathrm{Hg}^{2+}$ by the fluorescence spectrum. The enhancement of fluorescence intensity of the probe solution containing $\mathrm{Hg}^{2+}$ and $\mathrm{H}_{2} \mathrm{O}_{2}$ was very significant, which could reach 350-fold stronger than that of the blank probe solution. There was a good linear relationship in the range of $0-2 \mu \mathrm{M} \mathrm{Hg}^{2+}$, and the low detection limit was $0.3 \mathrm{nM}$ (on the basis of $3 \sigma /$ slope). The probe showed excellent solubility in water. More importantly, the response of probe HCDC to $\mathrm{Hg}^{2+}$ in real water samples was also satisfactory. All these remarkable advantages of this new probe suggest that this probe will have excellent application prospect in the detection of mercury.

\section{Conflicts of interest}

There are no conflicts of interest to declare.

\section{Acknowledgements}

This work was supported by the National Nature Science Foundation of China (No. 21777053), Major Livelihood Projects of Jinan (SHMS2015-3-01), the Municipal Development and Reform Commission Project of Jinan (2016JSFW02Z0307), and Water Conservancy Science and Technology project of Shandong Province (SDSLKY201606).

\section{References}

1 J. Wu, W. Jiang, A. Deng, Y. Shen, W. Jiang and R. Tian, Sens. Actuators, B, 2016, 234, 691-702.

2 R. Zhang and W. Chen, Biosens. Bioelectron., 2014, 55, 83-90.

3 B. Zhu, J. Zhao, H. Yu, L. Yan, Q. Wei and B. Du, Opt. Mater., 2013, 35, 2220-2225.

4 K. Kala, P. Vineetha and N. Manoj, New J. Chem., 2017, 41, 5176-5181. 
5 Y. Ge, X. Xing, A. Liu, R. Ji, S. Shen and X. Cao, Dyes Pigm., 2017, 146, 136-142.

6 Y. Zhou, X. He, H. Chen, Y. Wang, S. Xiao, N. Zhang, D. Li and K. Zheng, Sens. Actuators, B, 2017, 247, 626-631.

7 R. Zou, X. Zeng, G. Luo, Y. Qiu, B. Zhang, Y. Xu, H. Wu and H. Yao, Fuel, 2016, 186, 215-221.

8 W. Shi, S. Zhao, Y. Su, Y. Hui and Z. Xie, New J. Chem., 2016, 40, 7814-7820.

9 S. Ding, M. Dong, Y. Wang, Y. Chen, H. Wang, C. Su and W. Wang, J. Am. Chem. Soc., 2016, 138, 3031-3037.

10 S. Zhang, J. Geng, W. Yang and X. Zhang, RSC Adv., 2014, 4, 12596-12600.

11 Q. Mei, R. Tian, Y. Shi, Q. Hua, C. Chen and B. Tong, New J. Chem., 2016, 40, 2333-2342.

12 J. Zang, C. Li, K. Zhou, H. Dong, B. Chen, F. Wang and G. Zhao, Anal. Chem., 2016, 88, 10275-10283.

13 C. Zhang, L. Zou, D. Wang and L. Zhang, J. Photochem. Photobiol., A, 2017, 332, 440-452.

14 A. Afaneh and G. Schreckenbach, J. Phys. Chem. A, 2015, 119, 8106-8116.

15 A. Kora and L. Rastogi, Sens. Actuators, B, 2018, 254, 690-700.

16 M. Wani, N. Thakur, M. Pandey and R. Pandey, New J. Chem., 2017, 41, 10000-10008.

17 N. Sakly, W. Marzouk, H. Ouada and H. Majdoub, Sens. Actuators, B, 2017, 253, 918-927.

18 L. Yang, Y. Su, Y. Geng, H. Xiong, J. Han, Q. Fang and X. Song, Org. Biomol. Chem., 2018, 16, 5036-5042.

19 N. Wang, M. Lin, H. Dai and H. Ma, Biosens. Bioelectron., 2016, 79, 320-326.

20 N. Mir, A. Heidari, H. Beyzaei, S. Mirkazehi-Rigi and P. Karimi, Chem. Eng. J., 2017, 327, 648-655.

21 H. Cheng, C. Wu, L. Shen, J. Liu and Z. Xu, Anal. Chim. Acta, 2014, 828, 9-16.

22 H. Agarwalla, P. Mahajan, D. Sahu, N. Taye, B. Ganguly, S. Mhaske, S. Chattopadhyay and A. Das, Inorg. Chem., 2016, 55, 12052-12060.

23 D. Dinda, B. Shaw and S. Saha, ACS Appl. Mater. Interfaces, 2015, 7, 14743-14749.

24 H. Zhou, L. Sun, W. Chen, G. Tian, Y. Chen, Y. Li and J. Su, Tetrahedron, 2016, 72, 2300-2305.

25 Q. Wang, Y. Xu, Y. Hou, Y. Wang, M. Yan, X. Zhang and H. Wang, RSC Adv., 2016, 6, 114685-114689.

26 W. Liu, D. Zhang, B. Ni, J. Li, H. Weng and Y. Ye, Sens. Actuators, B, 2019, 284, 330-336.
27 X. Yang, W. Liu, J. Tang, P. Li, H. Weng, Y. Ye, M. Xian, B. Tang and Y. Zhao, Chem. Commun., 2018, 54, 1138711390.

28 B. Zhu, Z. Wang, Z. Zhao, W. Shu, M. Zhang, L. Wu, C. Liu, Q. Duan and P. Jia, Sens. Actuators, B, 2018, 262, 380-385.

29 B. Zhang, X. Yang, R. Zhang, Y. Liu, X. Ren, M. Xian, Y. Ye and Y. Zhao, Anal. Chem., 2017, 89, 10384-10390.

30 B. Zhu, L. Wu, H. Zhu, Z. Wang, Q. Duan, Z. Fang, P. Jia, Z. Li and C. Liu, Sens. Actuators, B, 2018, 269, 1-7.

31 J. Xu, J. Pan, X. Jiang, C. Qin, L. Zeng, H. Zhang and J. Zhang, Biosens. Bioelectron., 2016, 77, 725-732.

32 W. Niu, L. Guo, Y. Li, S. Shuang, C. Dong and M. Wong, Anal. Chem., 2017, 89, 11514-11519.

33 B. Zhu, L. Wu, M. Zhang, Y. Wang, C. Liu, Z. Wang, Q. Duan and P. Jia, Biosens. Bioelectron., 2018, 107, 218-223.

34 Y. Gao, T. Ma, Z. Ou, W. Cai, G. Yang, Y. Li, M. Xu and Q. Li, Talanta, 2018, 178, 663-669.

35 B. Zhu, W. Wang, L. Liu, H. Jiang, B. Du and Q. Wei, Sens. Actuators, B, 2014, 191, 605-611.

36 M. Jonaghani and H. Zali-Boeini, Spectrochim. Acta, Part A, 2017, 178, 66-70.

37 Y. Ge, A. Liu, R. Ji, S. Shen and X. Cao, Sens. Actuators, B, 2017, 251, 410-415.

38 K. Tayade, B. Bondhopadhyay, A. Basu, G. Chaitanya, S. Sahoo, N. Singh, S. Attarde and A. Kuwar, Talanta, 2014, 122, 16-22.

39 J. Xu, Z. Xu, Z. Wang, C. Liu, B. Zhu, X. Wang, K. Wang, J. Wang and G. Sang, Luminescence, 2017, 33, 219-224.

40 Q. Duan, H. Zhu, C. Liu, R. Yuan, Z. Fang, Z. Wang, P. Jia, Z. Li, W. Sheng and B. Zhu, Analyst, 2019, 144, 1426-1432.

41 Q. Duan, X. Lv, C. Liu, Z. Geng, F. Zhang, W. Sheng, Z. Wang, P. Jia, Z. Li, H. Zhu and B. Zhu, Ind. Eng. Chem. Res., 2019, 58, 11-17.

42 B. Zhu, L. Wu, M. Zhang, Y. Wang, Z. Zhao, Z. Wang, Q. Duan, P. Jia and C. Liu, Sens. Actuators, B, 2018, 263, 103-108.

43 Q. Duan, P. Jia, Z. Zhuang, C. Liu, X. Zhang, Z. Wang, W. Sheng, Z. Li, H. Zhu, B. Zhu and X. Zhang, Anal. Chem., 2019, 91, 2163-2168.

44 P. Jia, Z. Zhuang, C. Liu, Z. Wang, Q. Duan, Z. Liu, H. Zhu, B. Du, B. Zhu, W. Sheng and B. Kang, Anal. Chim. Acta, 2019, 1049, 219-225. 